\title{
Enhancing Ecosystem Services Management in Protected Areas Through Participatory System Dynamics Modelling
}

\begin{abstract}
Ecosystem services (ES) depend on coupled ecological and socioeconomic processes. We propose participatory modelling as a tool for sharing and co-creating knowledge about processes supporting (or eroding) local ES. The proposal consists of an open library of introductory ES dynamic models to be tailored for each case study. Such a library is illustrated by two ES examples and five models, published in an open-access web-platform. The results can contribute to the improvement of both analysis and deliberation, helping managers to design better policies and stakeholders to better formulate expectations.
\end{abstract}

\author{
Rocco Scolozzi ${ }^{1,2 *}$, Uta Schirpke ${ }^{3,4}$, \\ Davide Geneletti2,5 \\ 1) University of Trento, Department \\ of Sociology and Social Research, \\ Italy \\ 2) skopìa s.r.l. Anticipation Services ${ }^{\circledR}$, \\ Italy \\ 3) University of Innsbruck, \\ Department of Ecology, Austria \\ 4) Eurac Research, Institute for Alpine \\ Environment, Italy \\ 5) University of Trento, Department \\ of Civil, environmental and \\ mechanical engineering, Italy \\ *Corresponding author: Rocco \\ Scolozzi , University of Trento, \\ Department of Sociology and Social \\ Research, via Verdi 26, 38122 \\ Trento, Italy. \\ Email: rocco.scolozzi@unitn.it
}

\section{Keywords:}

Ecosystem services; Social-ecological systems; System dynamics;

Participatory modelling; Stakeholder engagement. 


\section{Introduction}

Although relationships between biodiversity and ecosystem services (ES) are very complex (Mace et al. 2012), it is widely acknowledged that biodiversity has general positive effects on many ES, which can be defined as the benefits that human populations derive from ecosystems (Millennium Ecosystem Assessment 2003). As natural environments are increasingly under pressure due to agricultural intensification, industrialisation and urbanisation (Cumming et al. 2014), protected areas are of extreme importance for providing ES, and particularly regulating and cultural (Watson et al. 2014). High expectations are therefore associated with the conservation of biodiversity and ES in protected areas (Larsen et al. 2015), although many protected areas suffer from ineffective management and struggle to adequately protect their natural capital (Butchart et al. 2012).

Protected area authorities are usually faced with environmental issues, such as degradation of habitats, fragmentation, and climate change, as well as with constraints associated with funding, conflicts with local stakeholders, and an increasing demand for recreational activities (Brandon et al. 2005). Moreover, they are often overwhelmed by internal pressures (between institutional obligations and duties, social demands, and economic drivers) and are limited by time and human resources to face the increasing complexity of socio-ecological systems (Scolozzi et al. 2014). To protect both biodiversity and ES, a key aspect in the successful management of protected areas is the involvement of local stakeholders. Participative approaches allow more effective and inclusive discussions to be conducted with different stakeholders and support related decision-making process (Antunes et al. 2009).

It is increasingly recognised that ES are co-produced by ecosystems and human agents by means of labour, technology or financial resources (Palomo et al. 2014; Partelow \& Winkler 2016), resulting in socioecological systems combining ecological, social, and economic complexity. The level of ES provision depends consequently not only on environmental conditions, but also on human interactions, including feedbacks, among ecological and socioeconomic processes (Palomo et al. 2014; Partelow $\&$ Winkler 2016). Hence, a deeper understanding of socio-ecological systems is crucial for successfully managing $E S$, including social network relations, interaction and linkages among multiple ES (Bennett et al. 2009).

Although methods for the assessment of ES have advanced considerably during the past decades by developing various methods and indicators, ranging from qualitative mapping exercises and quantitative approaches to monetary valuation methods (Barth \& Döll 2016; Darvill \& Lindo 2015), these assessment approaches may not be enough to anticipate the unintended effects of management actions. Several experimental studies about the performance of people confronted with complex dynamic systems revealed that they were unable to correctly infer how these systems will behave or how they should be managed (Sweeney \& Sterman 2000). Management strategies that are unaware of system complexity may cause negative cumulative impacts, such as unexpected ecosystem degradation and the unsustainable use of habitats, both of which affect ES provision.

Recently, ES approaches were integrated with participatory modelling approaches, for example byusing a participative mental model approach (Moreno et al. 2014), Bayesian networks (PérezMiñana 2016; Smith et al. 2018), or in combination with opinion dynamics models to simulate decisionmaking in relation to payments for ecosystem services (Sun \& Müller 2013).

We propose a general framework based on system dynamics (SD) models to support managers and stakeholders in protected areas to address the interactions between human activities and the environment. Such a framework consists of a modelling method guidance, "introductory models" (or pre-models) and an open web-platform,where to share and customize the pre-models as well as to simulate the management options included in the customized models. The pre-models are intended to be generic enough to grasp the common dynamics 
of each ES and simple enough to be understood by stakeholders, managers and the different experts potentially involved (e.g. sociologists, environmental professionals, economists). The expected outcome is the promotion of "boundary objects" (Black 2013), representing socially constructed understanding of local social-ecological systems to share among people with different roles in the management or maintenance of ecosystems (Abson et al. 2014). Our approach builds on the experiencesconducted in the European project LIFE+ "Making Good Natura" (Marino et al. 2014; Schirpke et al. 2017; for details about the project see www.lifemgnserviziecosistemici.eu).

In the following sections, we first introduce the SD approach.Then, we present the proposed framework through a couple of pre-models for provisioning and cultural ES, considering the perspective of protected area managers.

\subsection{Participatory system dynamics modelling: an overview}

SD is a rigorous method of system description, which assists feedback analysis and simulation of the effects of alternative system structures, as in scenarios or alternative policies (Forrester 1987). The aim of SD modelling is to obtain insights about the problem/system and to identify leverage points on which to act to change the dynamics (Senge 1990). SD models are management tools that help to compare strategies, in contrast to mathematical models aimed at forecasting variable values.

A key assumption of SD is that the behaviour of a system emerges from its structure, through causeeffect relationships and feedback loops, rather than from the values of individual variables, and that the leverage points increase their effectiveness with the depth of system organizational level in a hierarchical framework of complexity (Meadows 1999). A modelling process using SD consists of five iterative steps (Sterman 2000):

- Problem articulation

- Formulating dynamic hypothesis

- Formulating a simulation model
- Testing policy or management options

- Policy design and evaluation (feedback to Step 1 and iteration)

The first two steps concern qualitative modelling, i.e. the system's conceptualization, while the other three steps concern computer-based modelling for quantitative simulation. In particular, the second step leads to the development of an influence diagram, or causal loop diagram, making it possible to conceptualize the dynamics of a complex system or problem, to share mental models (making them explicit) between individuals and groups, and to communicate assumed important feedback loops at the source of the problem(s) (Sterman 2000). Such a causal loop diagram (CLD) highlights both the variables of a system and the links between these variables in order to identify feedback loops.

SD modelling with stakeholders, also named "group model building" (GMB, Vennix, 1999) or "mediated modelling" (Antunes et al., 2006), has been shown to be effective at improving the understanding of complex environmental problems, bringing a valued contribution to environmental decisionmaking (Videira et al. 2003; Rouwette et al. 2000). In a GMB project, the participants develop one or several models during structured sessions with the help of a facilitator. GMB promotes elicitation of participants' knowledge and mental models, helping to articulate and reframe perceptions, and create maps of the feedback structure of a problem from those perceptions (Forrester 1987); furthermore, SD simulations make it possible to assess the dynamics of those maps and test new policies (Chen et al. 2014).

Two main objectives drive the participatory modelling process: (1) to increase understanding and sharingknowledge about a system and its dynamics under various conditions; and (2) to identify and clarify the impacts of solutions to a given problem, supporting decision making, policy, regulation or management (Voinov \& Bousquet 2010). Accordingly, stakeholders may be involved, through $\mathrm{GMB}$, in different types of interactions (Lynam et al. 2007): where they provide knowledge, values or preferences to a diagnosis phase (data collection); where, with experts they jointly develop 
synthesis and co-learning (structuring the problem and simulating hypothesis); where they are included in a joint decision-making process (testing policies).

\subsection{Participatory modelling for ES management using system dynamics}

Both SD and ES are topics with a vast literature and scholarly communities (e.g, Systems Dynamic Society; Ecosystem Services Partnership), but with few attempts to bridge them (e.g. Batker et al. 2010; Costanza et al. 2007). Here, we propose a perspective of collaboratively building and applying system dynamics models (SDM) for specific ES, to be included in policy or management making. The approach can be progressively implemented in five steps with different objectives, requiring different resources along a transdisciplinary process (Figure 1) that integrates scientific and societal knowledge to address societal problems (Lang et al. 2012).

The focus of this article is on the first two steps concerning qualitative modelling to support the conceptualization of "ES system", then to facilitate sharing a general understanding of possible dynamics and sketching introductory dynamic hypotheses about possible consequences of management policy. Such steps are expected to prepare the ground for more quantitative development of sitebased dynamic models, on which to ground specific simulation and test alternative plans.
To assist in the starting of GMB projects for ES in the context of protected areas, we propose simplified generic dynamic models, as "introductory models" (or pre-models), with the following purposes:

- To represent the main and general variables involved in the process of reproduction (or provision) of the ES.

- To understand and visualise feedbacks between possible management measures and system variables.

- To provide managers with basic but systemic information to enable further development of specific dynamic models for their sites.

Such generic and qualitative SD models are intended as starting points of modelling processes, covering the first steps of the iterative cycle previously mentioned (Figure 1). The pre-models are based on common knowledge from scientific literature, from experts and from existing models (Ford 1999). The variables in the pre-models (see following sections) are to be considered only in qualitative terms; in effect, we (as humans) use "conceptual metaphors" by which we understand quantities in terms of directionality or, in other words, in terms of comparison (Lakoff \& Johnson 1980). Such qualitative approach follows a compromise between remaining general enough to model ES regardless of the site, but realistic enough to help further developments at the local level, e.g. by a local panel of experts and stakeholders.

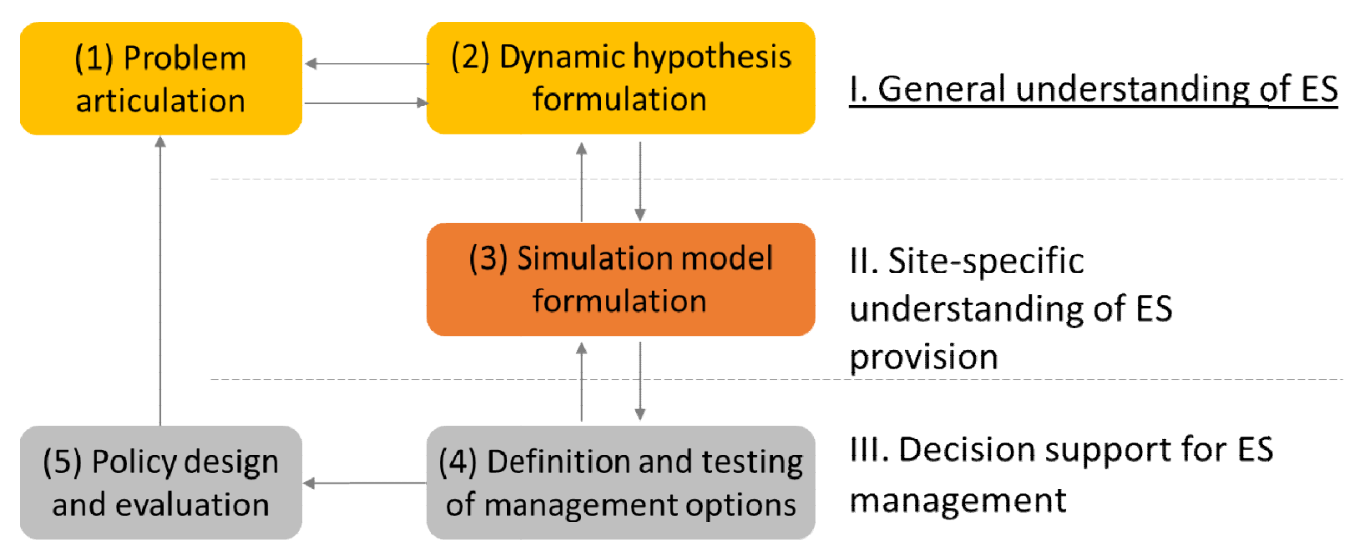

Figure 1: Framework for SD model building for ES, with different levels of development and support for decision making (modified after Sterman, 2000); the examples presented in this study refer to the first level, including steps (1) and (2). 
In the following sections, we illustrate the process of SD model building, presenting examples of problem articulation (through causal loop diagrams), and the design of dynamic hypotheses and introductory simulation models. The models are developed and published in the web platform Insight Maker(C) (https://insightmaker.com; Fortmann-Roe 2014). Insight Maker is a recent web-based, generalpurpose simulation and modelling tool; this tool has been designed to make modelling and simulation accessible to a wide audience of users. Insight Maker was used because of several advantages and characteristics: it is open and free (Fortmann-Roe 2014); it provides a repository of models in which modellers can independently improve models (Belete et al. 2017), returning and sharing their findings with modellers or users (Argent et al. 2016); SD models can be presented through the storytelling tool by which the users, even those without any knowledge about SD, can be accompanied in understanding and using them for the simulation of policy options or scenarios, updating the variables and seeing the outcomes in real time (Sturmberg et al. 2013).

\section{Pre-models of provisioning ecosystem services}

\subsection{Problem articulation and dynamic hypothesis}

Provisioning services are ES that provide the material or energy outputs from ecosystems that people can use such as food, water, and other resources (TEEB 2010). In a protected area, the service may entail the supply of game species, timber, and mushrooms for example.This resembles the process of reproduction of a renewable resource, characterised by logistic growth (Tsoularis \& Wallace 2002).The limit to growth is influenced by internal factors, such as carrying capacity (and the related gap between the actual level of related variable and the maximum value/carrying capacity), and by external factors, such as extraction or withdrawal. Logistic dynamics usually appear in systems in which the "regeneration" follows an exponential growth as long asstock is far from the carrying capacity

Table 1: Introductory simulation models corresponding to different types of contexts for recreational services. Key variables define the main dynamics of interest; management variables can be addressed by policy to influence such dynamics.

\begin{tabular}{|c|c|c|c|c|}
\hline Model & Type of system & Key variables & $\begin{array}{c}\text { Management } \\
\text { variables }\end{array}$ & Web links \\
\hline P1 & $\begin{array}{l}\text { natural renewable } \\
\text { resource }\end{array}$ & - carrying capacity & - Extraction & https://bit.ly/2UtEysc \\
\hline P2 & $\begin{array}{l}\text { natural renewable } \\
\text { resource }\end{array}$ & $\begin{array}{ll}\text { - } & \text { carrying capacity } \\
\text { - } & \text { biodiversity } \\
\text { (proxy) }\end{array}$ & $\begin{array}{ll}\text { - } & \text { Extraction } \\
\text { - } & \text { Habitat area }\end{array}$ & https://bit.ly/2v5cfRW \\
\hline C1 & $\begin{array}{l}\text { Remote areas with } \\
\text { reduced human } \\
\text { presence }\end{array}$ & $\begin{array}{l}\text { - Environmental } \\
\text { quality } \\
\text { - } \text { Visitors }\end{array}$ & - Marketing & https://bit.ly/2vh5vAj \\
\hline C2 & $\begin{array}{l}\text { Natural areas with } \\
\text { margin for } \\
\text { environmental } \\
\text { improvement }\end{array}$ & $\begin{array}{l}\text { - Environmental } \\
\text { quality } \\
\text { - Visitors }\end{array}$ & $\begin{array}{l}\text { - } \text { Marketing } \\
\text { Investments on } \\
\text { environment } \\
\text { quality }\end{array}$ & https://bit.ly/2Ps0m1D \\
\hline C3 & $\begin{array}{l}\text { Areas where } \\
\text { infrastructure could } \\
\text { be developed }\end{array}$ & $\begin{array}{ll}\text { - } & \text { Environmental } \\
\text { - } & \text { quality } \\
\text { - } & \text { (Touitors } \\
& \text { infrastructures }\end{array}$ & $\begin{array}{ll}\text { - } & \text { Marketing } \\
\text { - Investments on } \\
\text { environment } \\
\text { quality } \\
\text { - } \quad \text { Artificial" } \\
\text { attractiveness }\end{array}$ & https://bit.ly/2GB2ose \\
\hline
\end{tabular}


(the related gap is large), but the dynamic follows a saturation curve as the gap reaches zero. In general, the supply of this ES is sustainable if the extraction rate is less than the reproduction rate. The term gap in Figure 2, i.e. the difference between the current "stock" and maximum possible stock (associated to the specific carrying capacity), is used to highlight the role of carry capacity in balancing the growth; such difference limits the regeneration rather the stock alone.

Figure 2, like Figure 6 and Figure 7, follows the graphical conventions of causal loop diagrams, in which the arrows represent a causal relationship between the variables involved and have a polarity (+ or -) that represents the type of dynamics, in other words: a link with a ", ${ }^{\text {" }}$ can be read as , a change in A will cause a change in $B$ in the same direction, both increasing and decreasing, on the contrary with" "the direction will be the opposite, if the first one increases the second one will decrease and vice versa (the color of the arrows is used here only to highlight the differences).

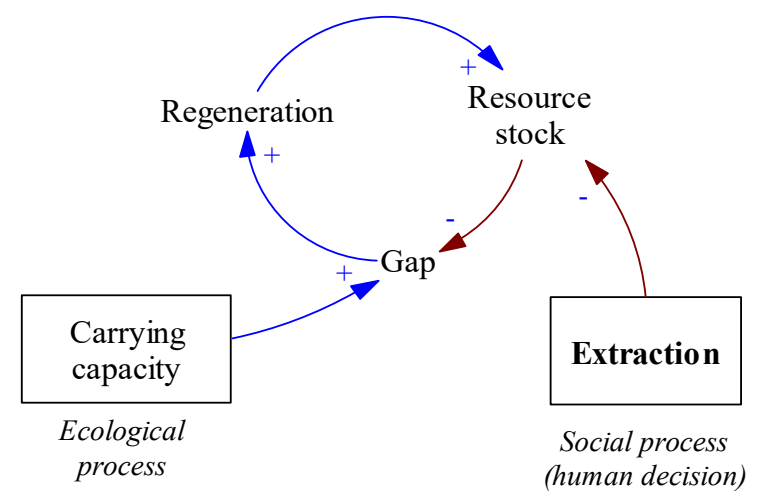

Figure 2: A causal loop diagram of provisioning ES (left): a balancing feedback loop is driven by the variables "carrying capacity" and "extraction".

\subsection{Basic simulation models ( $P 1$ and $P 2)$}

A basic model (Figure 3) shows the key element of a natural renewable resource: it can be extracted within the limits of the regeneration rate and the associated carrying capacity. The typical dynamic is a logistic curve.

Figure 3, like the 4, 8, 9 and 10, represents a stock and flow model, in which the stock variables are explained in the white boxes (these are elements of the system that accumulate over time, such as the level of water in a tank), the inlet and outlet flow variables regulate the level over time (such as the faucet and the outlet pipe in a tank). In the gray boxes the "management variables" are highlighted, these can be modified directly on the basis of decisions and interventions, to differentiate them from those of an ecological type or not directly controllabl

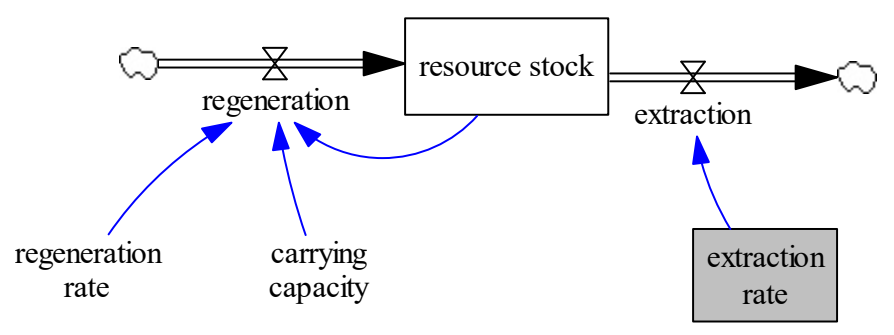

Figure 3: Basic model of provisioning services (P1), with the management variable extraction rate.

In a model slightly more realistic,the carrying capacity depends on the amount of habitat area, a second "management variable",in addition to extraction rate, that managers of protected areas could influence or that are expected to change after human interventions.

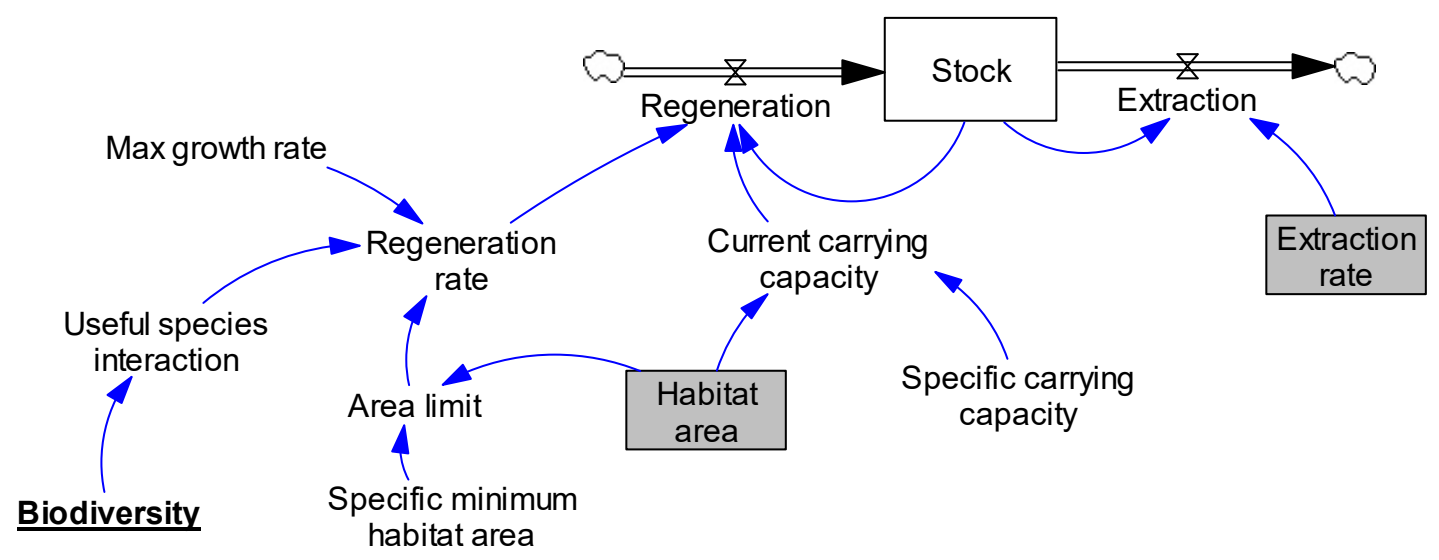

Figure 4: Model of provisioning services (P2), with management variables habitat area and extraction rate. 
In this model, the current regeneration rate is a function of a maximum specific regeneration rate, proper of interested resource-species (e.g. cubs per female), of local biodiversity and of the area limit.

At this level of modelling, for learning purposes, biodiversity is intended in terms of the percentage of the expected species at the site; simplifying the biodiversity as the number of species, the best conditions are those where all species expected in the concerned ecosystem are present (the "right" set of species). Although the relationships between biodiversity and ES are more complex (Mace et al. 2012), we assume that such simplification is acceptable for the purpose of pre-models and the expected qualitative results. Besides, in Europe most habitats included in protected area are relatively well known, even the norms (see Habitat Directive) contain detailed lists of the speciesthat are relevant for nature conservation. From the perspective of managers of protected areas, the number of species is usually the easiest, often the unique, indicator on biodiversity.

To consider the uncertainty in the relationship between biodiversity and provision of ES, we used a random (function) multiplier of the current regeneration rate (labelled useful species interaction). The role of random multiplier is to obtain the random trend emulating the variability over the years of the interactions among the species and environmental conditions, without any other information available. The area limit includes the specific minimum habitat area, under which the resource (e.g. roe-deer) cannot reproduce. Such variable is arbitrarily defined here, in further specific development it should be related to the specific species-resources at the focus (e.g. roe-deer, hare). The current carrying capacity is related to the habitat area and the specific carrying capacity, measured in terms of resource unit per area (e.g. number of roedeer/100 ha). Such specific carrying capacity can be inferred from ecological knowledge or local data.

In the equations of the model (see online models), the parameter values are not empirically based but arbitrarily chosen to illustrate possible dynamics of the modelled systems. With that purpose, after fixinganextraction rate, we simulated two didactichypotheses (Figure 5): a biodiversity loss (disappearing of $20 \%$ local species) and an increase in available habitat for a target species (e.g. after a spatial plan or an intervention of ecological

\section{Stock}

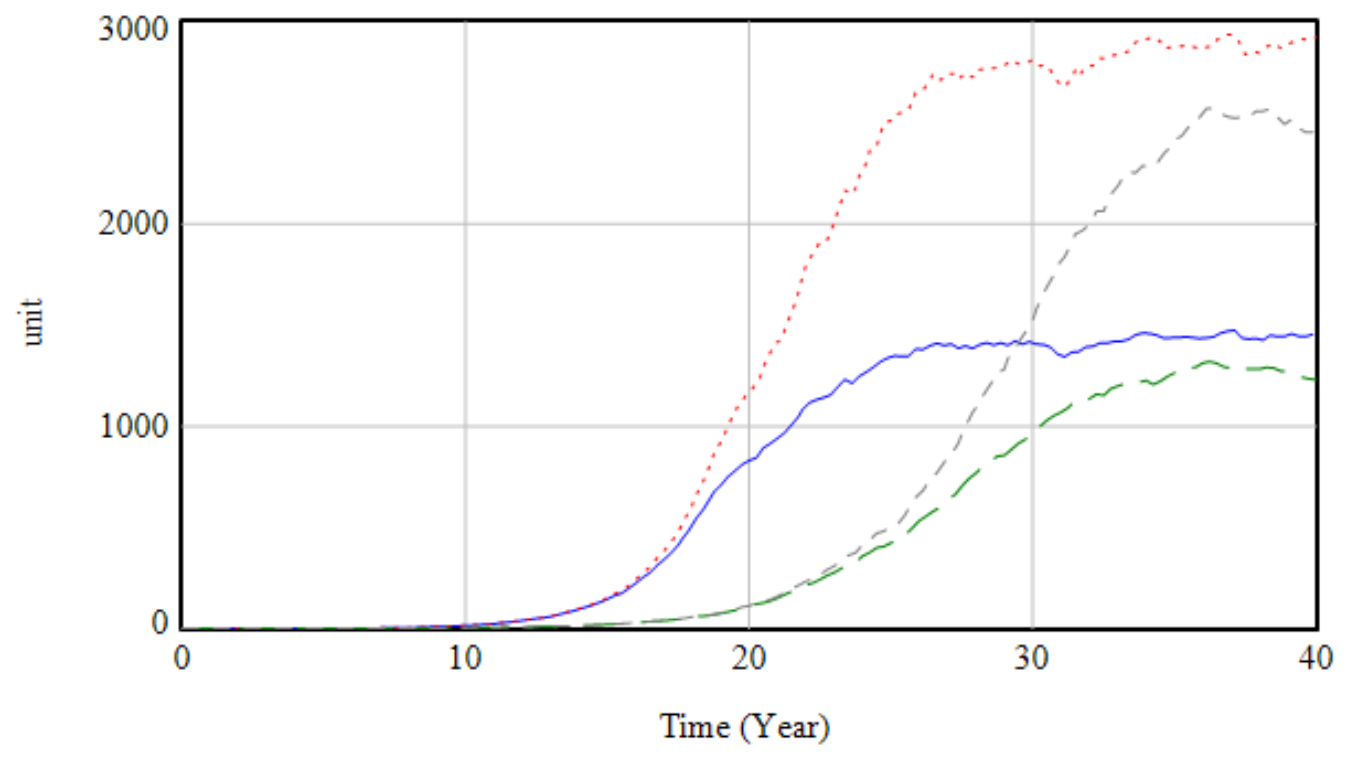

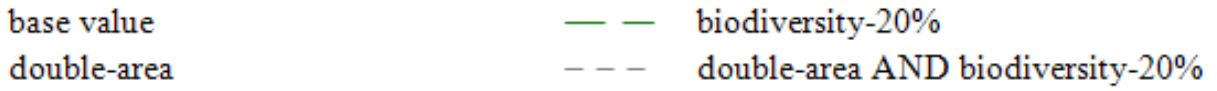

Figure 5: Simulations with P2 model for provisioning ES, exemplifying simulation of scenarios: baseline, loss in biodiversity, doubling of habitat area, combination of both. 
restoration). Due to the simplification specified above, the time graph of variables in Figure 5 should be read as a qualitative sketch of possible dynamics over time; the main message is that an equilibrium is reached for all different alternatives.

\subsection{Insights and applications for management}

This model aims at illustrating the possible dynamics of common environmental resources that naturally regenerate themselves and the role of biodiversity, extraction rate, habitat area and the associated carrying capacity.

A strong assumption lies behind the definition of "habitat area": this should have geographical and ecological qualities to support a vital local population of the species under question. This paves the way for insights and discussions with land managers on the suitability of habitats and their functional connectivity.The model may be useful for better understanding the resource's process of reproduction and for explaining it to the local population and stakeholders, furthermore, for demonstrating the importance of a required (functioning) habitat area and local biodiversity for supplying the ES. The simulations help to understand the equilibrium-seeking dynamic of the stock variable (related to the resource-species), in which the availability of "habitat area" defines the carrying capacity andlimits thegrowth of stock. The elementary lesson from this basic model is about the limitation of extraction (or consumption) of natural resourceswith a limited capacity of regeneration; by testing different rates of extraction, one can understandthe importance of regulating and knowing the rate of sustainable extraction.

\section{Pre-models for cultural ecosystem services (recreation)}

\subsection{Problem articulation and dynamic hypothesis}

Natural areas are considered to provide many recreational opportunities (Sonter et al. 2016), but the ES supply depends on the accessibility (AlaHulkko et al. 2016). Thus, the recreational value of a protected area is only supplied if it can be visited, i.e. only if the visitor or tourist can enjoy features such as views on the spot. Access depends not only on geography but also on dedicated touristic infrastructures (e.g. hiking trails, mountain huts) that facilitates the visit or enable recreational activities. This ES therefore partly depends on the natural component (ecosystems that offer recreational spaces and opportunities) and partly on the work of humans (enabling access and enjoyment of said spaces).

For natural (or protected) areas, different levels of possible human intervention and/or naturalness can be distinguished. For example, in remote areas (e.g. high-altitude ecosystems), human intervention is generally limited to the opening and maintenance of access tracks. In flat areas, naturally more accessible, the recreational value may depend more on artificial structures (e.g. bird watching towers) that make one site more attractive than another. We use the term "environmental quality" for this combination of biodiversity and human agency (e.g. the maintenance of specific habitats). The relation between the recreational value of a site and the environmental quality is a recurrent dynamic typical of nature-based tourism: the number of visitors increases with increasing environmental quality, but their increase sooner or later has negative effects on the environmental quality (Pickering and Hill 2007), leading again to lower visitor numbers. In SD terms, the process includes a negative, or "balancing", feedback cycle that reduces environmental quality and visitor numbers with respect to initial values (Figure 6), reaching an equilibrium. The variables visitors and environmental quality describe the recreational value of a site and may be linked by attractiveness and the level of environmental stress. In such terms, the cultural ES is not merely associated with an environmental context or to a tourism statistic, but, at least, to a couple of interlinked variables.

Management actions influence the recreational value with different effects on the environmental quality. The number of visitors can locally provide resources for investments for the improvement or maintenance of environmental quality (Figure 7, left). This creates two opposite feedback loops: the two can strike a balance that can result in the 

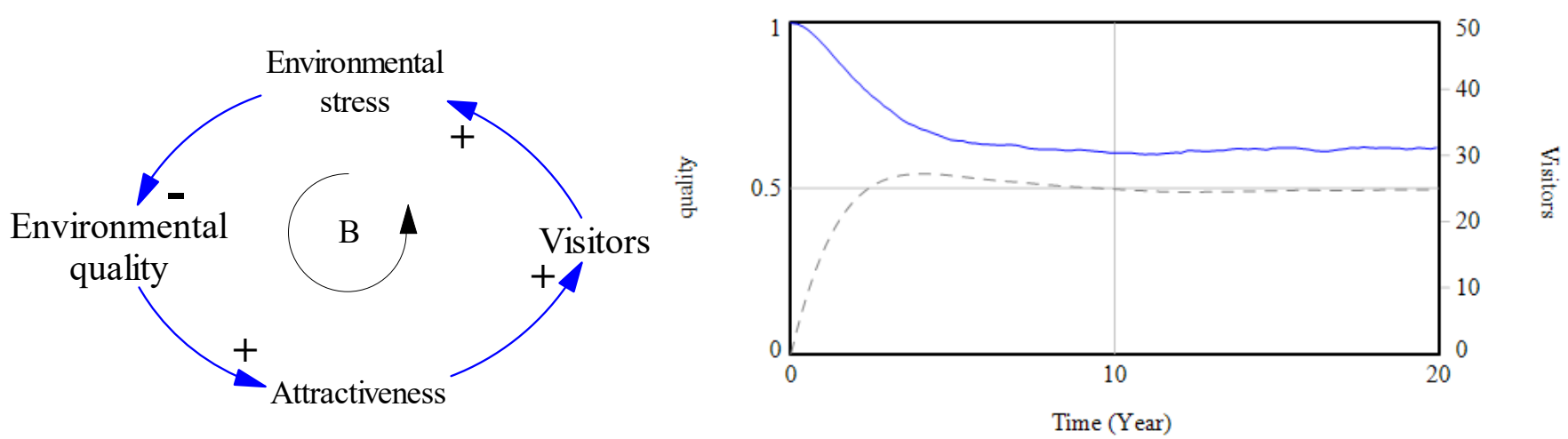

Figure 6: A causal loop diagram of recreational ecosystem services: one balancing (negative) feedback loop connects the number of visitors and environmental quality (left), with an exemplifying simulation showing the system equilibrium (right).
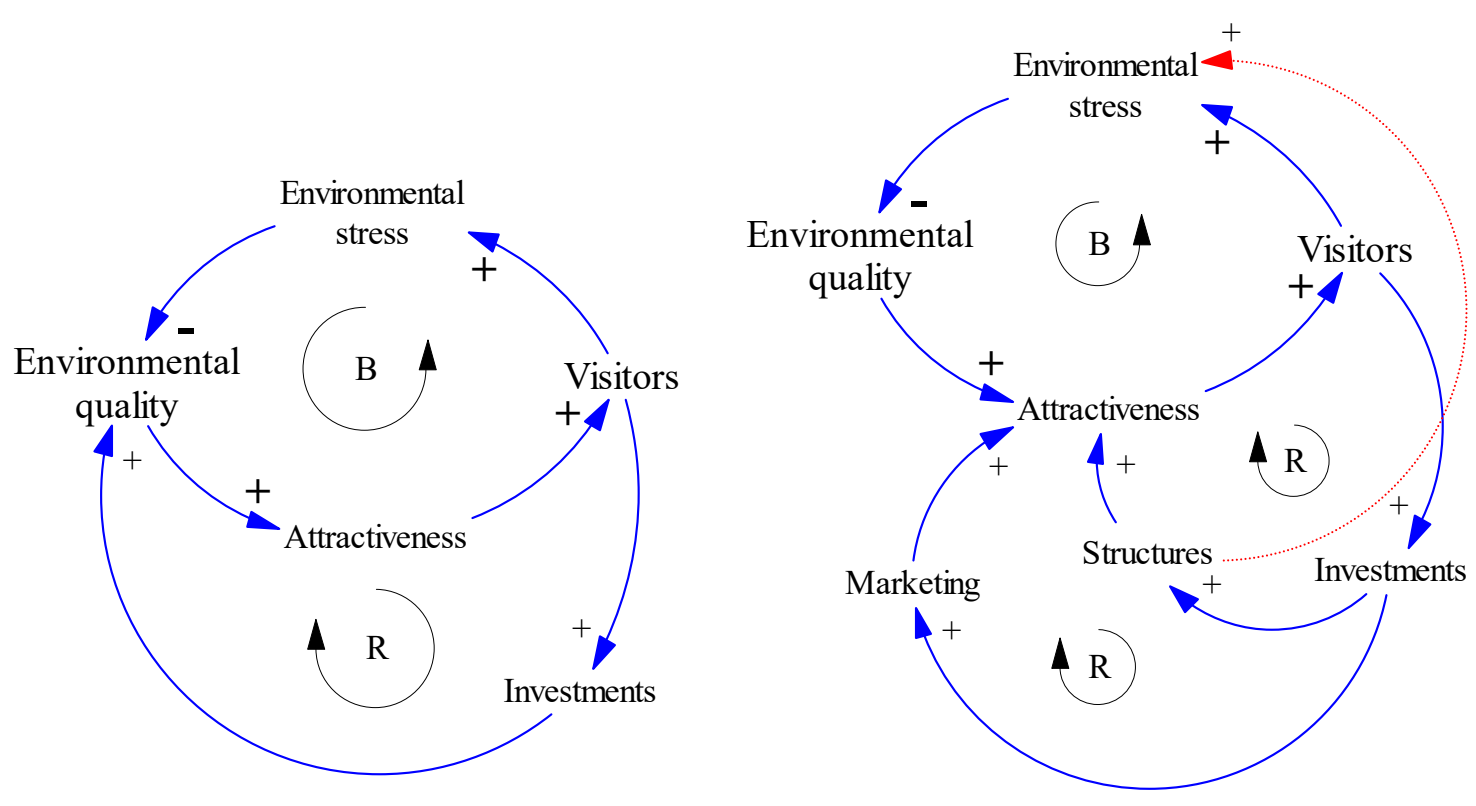

Figure 7: Two possible "recreational systems": with investments supporting the maintenance of environmental quality (left), with investments supporting the attractiveness of the site (right). The arrows with B and R stand for Balancing feedback loop and Reinforcing feedback loop.

sustainability of the recreational service (with an equilibrium at a higher level of environmental quality).

Unsustainable dynamics may occur if investments are aimed at increasing attractiveness through marketing and structures for recreational activities, without proportionally increasing or maintaining environmental quality. In these conditions, two feedback loops, decoupled from environmental quality (Figure 7, right) may destabilise the system: decreasing (or annulling) the stabilising function of the feedback between environmental quality and visitors, and leading to a rapid increase in environmental stress (no longer controlled internally by the system).

\subsection{Basic simulation models}

Considering the mentioned dynamics, different types of socio-ecological systems can be distinguished (Table 1), in which ecological and human variables are interdependent. 


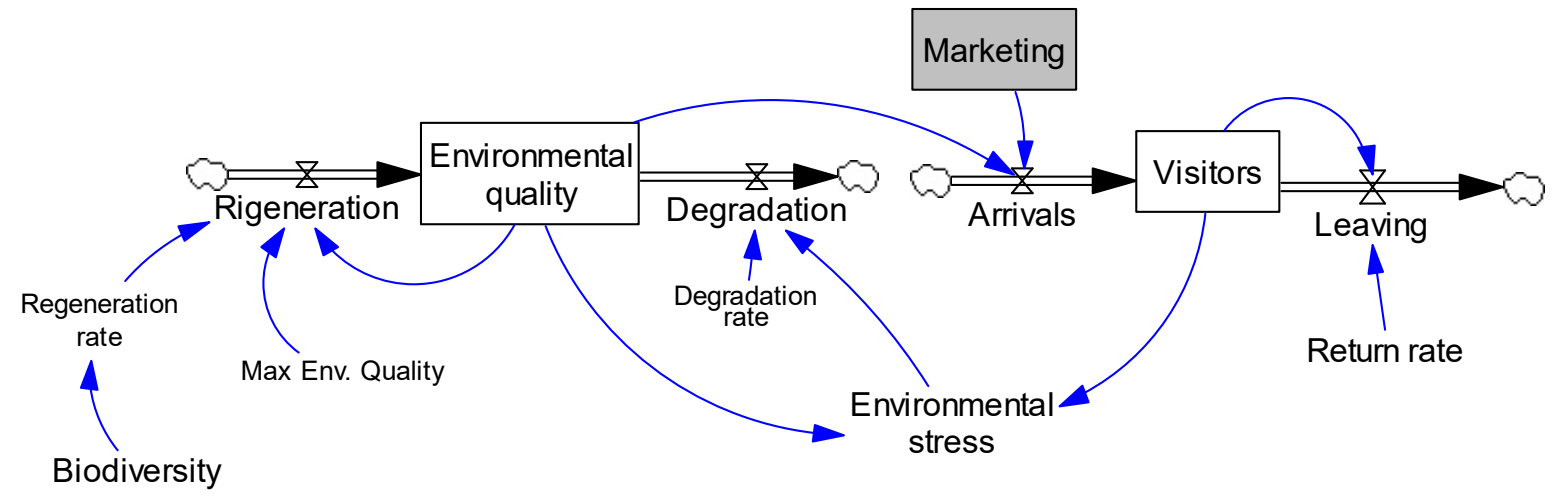

Figure 8: SD model C1, corresponding to the causal diagram of Figure 6.

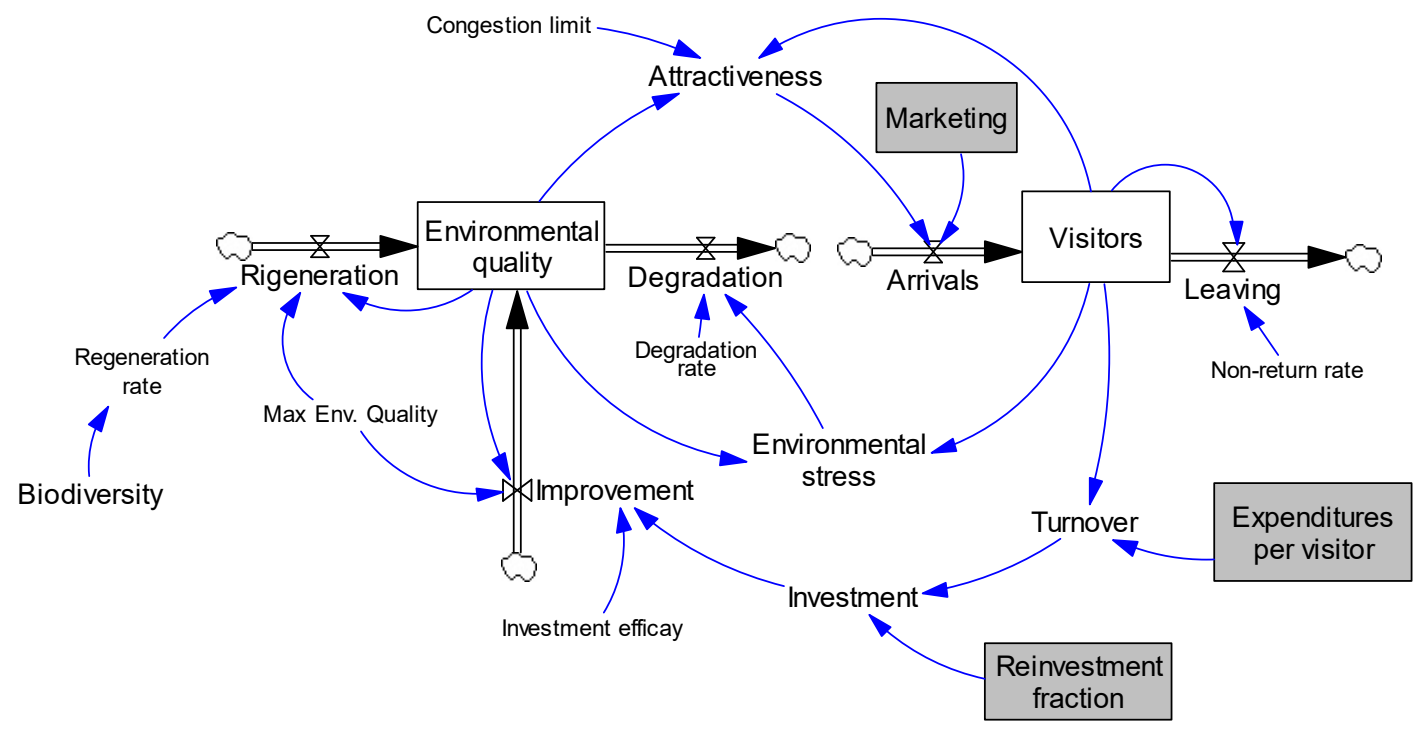

Figure 9: SD model C2, corresponding to the causal diagram of Figure 7 (left).

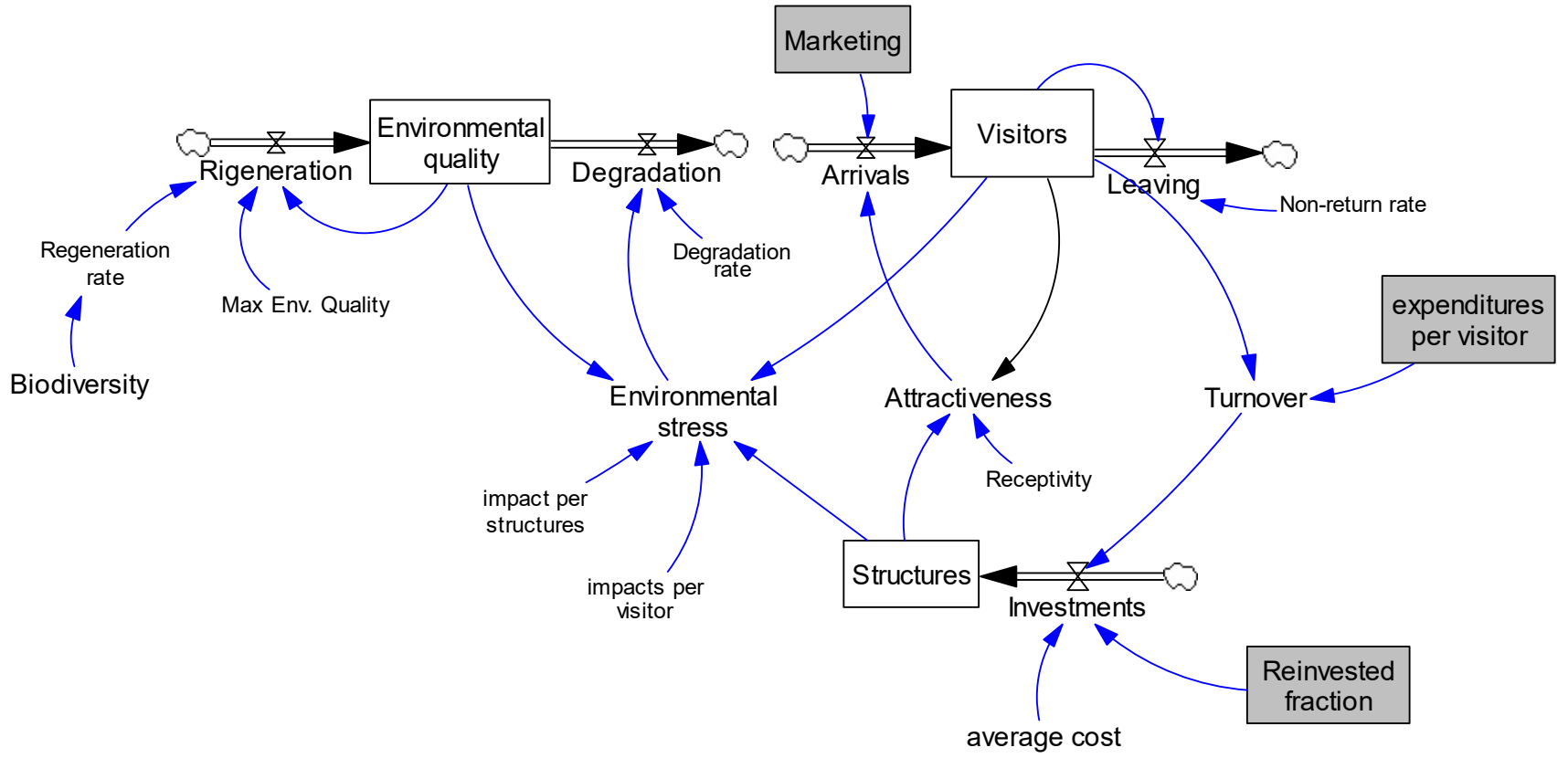

Figure 10: SD model C3, corresponding to the causal diagram of Figure 7 (right). 
In the basic model, the main (stock) variables are environmental quality and visitors; these are measured in a qualitative scale, without real references. The variable environmental stress considers the number of visitors and the level of environmental quality, assuming the environmental stress caused by a single visitor is greater at a site with the maximum environmental quality than at a degraded site. The number of visitors is initially set at 0 and oscillates around a level of equilibrium depending upon marketing success (higher visitor numbers) and environmental quality, realizing the negative (stabilizing) feedback loop.

At this stage of modelling, the values of all variables are not based on realistic estimates, the focus of interest being the understanding and making evident the dynamics between variables by modelling and simulation, i.e. whether variable values tend to decrease or increase under changed management conditions. Thus, the comparison between variables' dynamics is more relevant than their absolute values. Such variables could be scaled with real data and the models could be calibrated, in following the steps of modelling and simulation.

Nevertheless, the proposed models can depict some dynamics and can be used in collaborative discussion for environmental policymaking. The comparison between likely dynamics in different contexts, represented by the models $\mathrm{C} 1, \mathrm{C} 2$, and $\mathrm{C} 3$, clearly shows changes in dynamics of environmental quality and visitors.

\subsection{Insights and applications for management}

The models represent different realistic conditions, one in which managers and stakeholders dedicate part of revenue to the maintenance or conservation of environmental quality, e.g. conservation actions to preserve or restore specific ecosystems or maintenance of the trail network; in the other they are dedicated to improving the attractiveness without investing in environmental quality. The different outcomes are clearly shown in the diagrams and easy to communicate (Figure 11).

The results can be usedto support sustainable management of protected areas, as the models include several "management variables", such as expenditures per visitor, marketing, and re-invested fraction. Again, the values are purely fictitious and should be integrated and calibrated, through supplementary research and/or stakeholder participation. Nonetheless, the model simulations make it possible to explore interesting scenarios and to answer management questions such as: whichstrategy most increases the volume of the business and at whichprice for the environmental quality? For instance, in the model $\mathrm{C2}$, the best strategy appears to increasing the expenditures per visitor: this increases the environmental quality (with an impact identical to that derived from the option of doubling the re-invested fraction) and increases revenues (on the condition that the other variables are kept unchanged). Another example of application is related to the increase or improvement
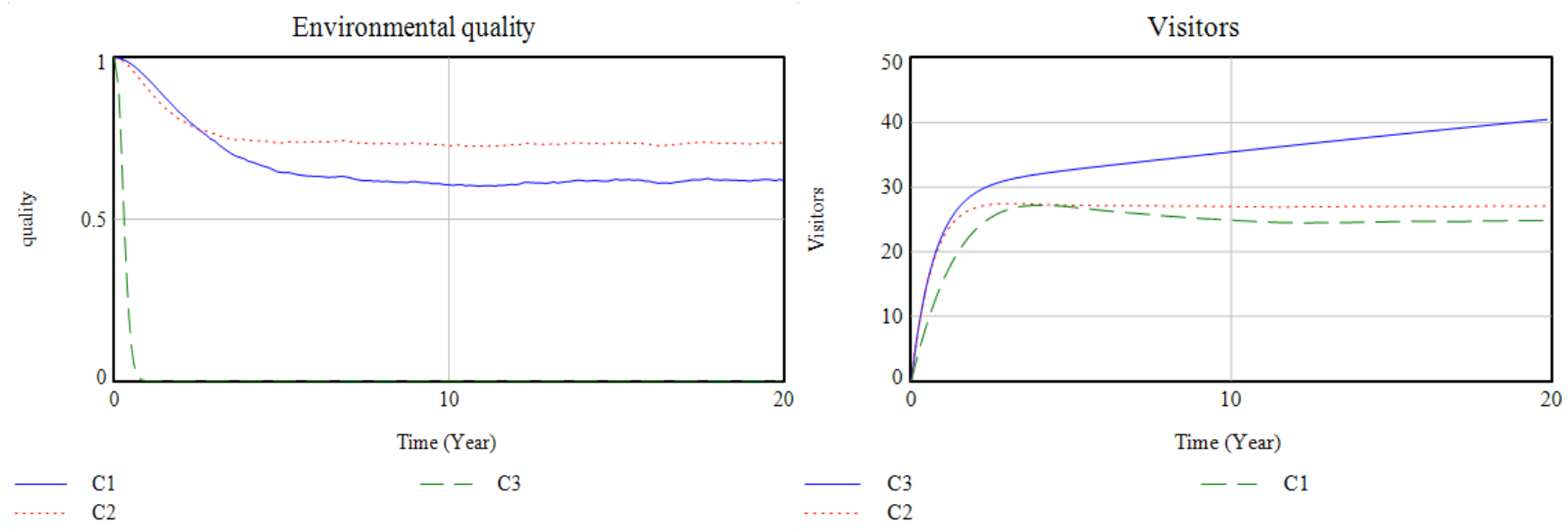

Figure 11: Comparison between different "recreational systems": the likely dynamics of environmental quality (left), the likely dynamics of visitor numbers (right). 
of touristic infrastructures in model C3. Investing into infrastructures such as hiking trails, touristic facilities (e.g. benches, fountains, catering) and information material influences the attractiveness of the protected area and consequently can increase visitor numbers. At the same time, environmental stress and pressure on biodiversity may increase, which then requires a thoughtful planning and concept of the investments to reduce the impact on biodiversity by guiding the visitors in the protected area.

\section{Discussion}

In this paper, we stress the importance of participatory model development process. The proposed generic models are to be considered as starting models suitable for a general understanding of the dynamics in the provision and benefiting of ES, which maylead to developing shared representations with the local communities (Black, 2013). From our experience, difficulties emerged fordecision-makers to understand the complexities of "their" socio-ecological system. This resulted in wishful strategies or plans, which howevermay neglect local system barriers to effective and durable collaboration among stakeholders and beneficiaries or be unaware of possible feedbacks that may cause negative and unexpected impacts in the future (e.g. visitor congestion and erosion of environmental quality).

While GMB applications for environmental management are increasing, those concerning ES (in protected areas) are not common yet. We proposed the perspective of GMB for SD modelling of ES to improve the understanding, the communication, and, accordingly, the management of ES. We focused on protected areas because, in our experience, in these contexts it is easier to identify and engage the relevant stakeholders (including the administrators and managers); anyhow, the same approach can be applied to any socio-ecological system in which the relevant actors are recognizable and might be involved.

The proposed system dynamic modelling is distinguished from the apparently similar one known as Fuzzy Cognitive Mapping (Gray et al. 2015; Özesmi \& Özesmi 2004). In the latter, the formalized schemes, even if using analogous signs (arrows with polarity), refer to relations between the knowledge elements (e.g. concepts, preferences) of a „mental maps" through which one can represent local knowledge (or knowledge held by stakeholders) and model decision making. In SD models, the arrows represent information or material flows or causeeffect relations between variables of systems (in our case: social-ecological systems); the SD models are tools for simulation of system conditions, providing information about of hypothetical states of observable variables (e.g. level of stock or quantity of a resource).

At a general level of understanding, the pre-models focus on exploring and understanding the complexity of ES provision; in a second step, the models include more specific variables concerning the ecosystems (or landscapes) under study (such as those related to the socio-cultural context). Where suitable data and SD experts are available, the pre-models should be further developed and used to design and check management options, anticipating their side effects and improving their formulation.

The pre-models presented here have several limitations, being hypothetical and generic, and based on theories and assumptions derived from general notions of ecology or environmental economics and from direct experience in the project LIFE MGN, rather thantested with data of a specific area. They are rather incomplete, as they only include the few main variables linked to possible management measures (e.g. "habitat area" rather than "vegetation growth" or other ecological variables). The variables have dummy values with an essentially qualitative meaning (often zero stands for minimum quantity or value, 1 or 10 stands for maximum quantity or value). For operational use, as the definition of actions for a site, these models are not sufficient, since they require calibration and verification with real data and, probably, reformulation with new variables.

Notwithstanding these limitations, the insights the simulations provide are useful for sharing knowledge and reframing the expectations from environmental 
policies or strategies. Most of the presented dynamics (system behaviours) are intuitive and well known when they are considered separately, but the systemic perspective provided by causal loop diagrams and semi-quantitative scenarios, resulting from simulations, provide clear and relevant information about the complexity of ES provision.

These SD models can reveal implicit assumptions that could be deleterious for the sustainable use or consumption of natural resources (see differences among the models $\mathrm{C} 2$ and $\mathrm{C} 3$ ), and they may sustain more cognisant discussions among stakeholders. Management problems and strategies can be defined from new and possibly varied perspectives (e.g. tourism, landscape ecology, biodiversity conservation) to develop more specific models for the sites and to simulate management scenarios. Modelling together with local stakeholders may be a way to bridge local knowledge (held by land managers, owners, beneficiaries in general) and scientific knowledge (by experts, academics, and researchers) (Spangenberg et al. 2015).

We proposed the use of Insight Maker(C) to present and to develop SD models of ES open to an interaction (simulation) by users. Simulations allow to bring the patterns we build to life and get a sense of the implications of the relations over time. It has been said that we as humans have a very limited capacity to understand the implications of two or more dynamic relations over time. Within Insight Maker@, stakeholders, even the ones without any previous knowledge of SD, can simulate and recognize possible patterns of the interested system. A simulation essentially does a time compression (or expansion) to allow us to consider the implications of the relations over time, an experience that would otherwise be very difficult to understand.

The ideal outcome of the use of a web-based open access platform for modelling and simulating is the creation of a library of basic SD models dedicated to ES, in which experts can download materials to develop their own models. Moreover, stakeholders can easily interact with the complexity of their "own" socio-ecological system, together building capacity for adaptive management (Westgate et al. 2013).
In this paper, we initiated such a library (open to interaction and improvement at the page "Explore insights" of insightmaker.com), considering two general classes of ES: provisioning services (food, raw materials) and cultural services (recreation value); further models for specific case studies are going to be developed concerning other ES, especially regulating services.

The participatory development of SD models of (local) ES entails a learning process in which the model users and developers (including locals, stakeholders, and communities) can develop a deep understanding about system structure and behaviour relationships; this may support both analysis and deliberation. This type of learning process may consist of double-loop learning (Argyris 1976) in which users/modellers can go beyond a trial-error-learning process (first learning loop or incremental learning) and can restructure the way they see the system reframing the assumptions (second learning loop) (Medema et al. 2014). Such progression may allow the managers to articulate better policies and the stakeholder to frame better expectations.

\section{Conclusions}

We proposed the use and development of system dynamics models concerning the processes underpinning ES and supporting their understanding, maintenance and sustainable management. We showed basic models, included in a"library of introductory ES models", to be used in startinglocal exercises of participatory modelling.The simplified models are helpful starting points to develop more operative dynamic models of ES; they allow the simulation of management scenarios and provide an immediate view of related possible consequences.

We believe the modelscan support a more operational understanding of the dynamics within ES by local stakeholders, facilitating more informed discussion among them. The attention to the time variable, typical of dynamic models, can help to spread among the decision-makers and stakeholders a 
medium-to-long term perspective (Hjorth \& Bagheri, 2006), necessary for the sustainable management of ecosystems and protected areas. Moreover, due to its replicability, the use of such tools in a open webbased platform may be of educational value on the topic of systems thinking applied to ES management for people with or without any previous background in SD modelling.

The next steps include further development and testing of the tailor-made models with real data and their potential use for sustainable ES management. Possible future developments include participatory modelling sessions for each area of interest (included or not in protected areas) and for each ES, by mixed groups of experts (with multidisciplinary backgrounds) and stakeholders, including citizens as well as public or private managers of landscapes.

\section{References}

Abson, D. J.; von Wehrden, H.; Baumgärtner, S.; Fischer, J.; Hanspach, J.; Härdtle, W.; Heinrichs, H. et al. 2014. Ecosystem Services as a Boundary Object for Sustainability. Ecological Economics 103, 29-37. DOI: 10.1016/j.ecolecon.2014.04.012

Ala-Hulkko, T.; Kotavaara, O.; Alahuhta, J.; Helle, P. \& Hjort, J. 2016. Introducing Accessibility Analysis in Mapping Cultural Ecosystem Services. Ecological Indicators 66, 416-427. DOI: 10.1016/j. ecolind.2016.02.013

Antunes, P.; Kallis, G.; Videira, N. \& Santos, R. 2009. Participation and Evaluation for Sustainable River Basin Governance. Ecological Economics 68 (4): 931-939. DOI: 10.1016/j.ecolecon.2008.12.004

Antunes, P.; Santos, R. \& Videira, N. 2006. Participatory Decision Making for Sustainable Development--the Use of Mediated Modelling Techniques. Land Use Policy 23 (1): 44-52.
Argent, R. M.; Sojda, R. S.; Giupponi, C.; Mc Intosh, B.; Voinov, A. A. \& Maier, H. R. 2016. Best Practices for Conceptual Modelling in Environmental Planning and Management. Environmental Modelling \& Software 80, 113-121. DOI: 10.1016/j. envsoft.2016.02.023

Argyris, C. 1976. Single-Loop and Double-Loop Models in Research on Decision Making. Administrative Science Quarterly 21 (3), 363-375.

Barth, N. C. \& Döll, P. 2016. Assessing the Ecosystem Service Flood Protection of a Riparian Forest by Applying a Cascade Approach. Ecosystem Services 21, Part A, 39-52. DOI: 10.1016/j. ecoser.2016.07.012

Batker, D.; de la Torre, I.; Costanza, R.; Swedeen, P.; Day, J.; Boumans, R. \& Bagstad, K. 2010. Gaining Ground - Wetlands, Hurricanes and the Economy: The Value of Restoring the Mississippi River Delta. Tacoma, WA: Earth Economics. https://www. eartheconomics.org/publications-archive (Date: 23.04.2019).

Belete, G. F.; Voinov, A. \& Laniak, G. F. 2017. An Overview of the Model Integration Process: From Pre-Integration Assessment to Testing. Environmental Modelling \& Software 87, 49-63. DOI: 10.1016/j.envsoft.2016.10.013

Bennett, E. M., Peterson, G. D. \& Gordon, L. J. 2009. Understanding Relationships among Multiple Ecosystem Services. Ecology Letters 12 (12), 13941404. DOI: 10.1111/j.1461-0248.2009.01387.x

Black, L. J. 2013. When Visuals Are Boundary Objects in System Dynamics Work. System Dynamics Review 29 (2): 70-86. DOI: 10.1002/sdr.1496

Brandon, K.; Gorenflo, L. J.; Rodrigues, A. S. L. \& Waller, R. W. 2005. Reconciling Biodiversity Conservation, People, Protected Areas, and Agricultural Suitability in Mexico. Livelihoods, Forests, and Conservation 33 (9), 1403-1418. DOI: 10.1016/j.worlddev.2004.10.005 
Butchart, S. H. M.; Scharlemann, J. P. W.; Evans, M. I.; Quader, S.; Aricò, S.; Arinaitwe, J.; Balman, M. et al. 2012. Protecting Important Sites for Biodiversity Contributes to Meeting Global Conservation Targets. PLOS ONE 7 (3), e32529. DOI: 10.1371/journal.pone.0032529

Chen, H.; Chang, Y. C. \& Chen, K. C. 2014. Integrated Wetland Management: An Analysis with Group Model Building Based on System Dynamics Model. Journal of Environmental Management 146, 309319. DOI: 10.1016/j.jenvman.2014.05.038

Costanza, R.; Leemans, R.; Boumans, R. \& Gaddis, E. 2007. Integrated Global Models. In R. Costanza, L. J. Graumlich, and W. Steffen (eds.): Sustainability or Collapse? An Integrated History and Future of People on Earth. MIT Press:Cambridge, MA.

Cumming, G. S.; Buerkert, A.; Hoffmann, E. M.; Schlecht, E.; von Cramon-Taubadel, S. \& Tscharntke, T. 2014. Implications of Agricultural Transitions and Urbanization for Ecosystem Services. Nature 515 (7525), 50-57. DOI: 10.1038/ nature13945

Darvill, R. \& Lindo, Z. 2015. Quantifying and Mapping Ecosystem Service Use across Stakeholder Groups: Implications for Conservation with Priorities for Cultural Values. Best Practices for Mapping. Ecosystem Services 13, 153-161. DOI: 10.1016/j. ecoser.2014.10.004

Ford, F.A. 1999. Modeling the Environment: An Introduction to System Dynamics Models of Environmental Systems. Island Press.

Forrester, J.W. 1987. Lessons from System Dynamics Modeling. System Dynamics Review 3 (2), 136149. DOI: $10.1002 / s d r .4260030205$

Fortmann-Roe, S. 2014. Insight Maker: A GeneralPurpose Tool for Web-Based Modeling \& Simulation. Simulation Modelling Practice and Theory 47, 28-45. DOI:10.1016/j. simpat.2014.03.013.
Gray, S.; Gray, S.; De Kok, J. L.; Helfgott, A.; O’Dwyer, B.; Jordan, R. \& Nyaki, A. 2015. Using Fuzzy Cognitive Mapping as a Participatory Approach to Analyze Change, Preferred States, and Perceived Resilience of Social-Ecological Systems. Ecology and Society 20 (2). DOI:10.5751/ES-07396200211.

Hjorth, P. \& Bagheri, A. 2006. Navigating towards Sustainable Development: A System Dynamics Approach. Futures 38 (1): 74-92. DOI:10.1016/j. futures.2005.04.005

Lakoff, G. \& Johnson, M. 1980. Conceptual Metaphor in Everyday Language. The Journal of Philosophy 77 (8), 453-486. DOI:10.2307/2025464.

Lang, D. J.; Wiek, A.; Bergmann, M.; Stauffacher, M.; Martens, P.; Moll, P.; Swilling, M. \& Thomas, C. J. 2012. Transdisciplinary Research in Sustainability Science: Practice, Principles, and Challenges. Sustainability Science 7 (1), 25-43. DOI:10.1007/ s11625-011-0149-x.

Larsen, F. W., Turner, W. R. \& Mittermeier, R. A. 2015. Will Protection of $17 \%$ of Land by 2020 Be Enough to Safeguard Biodiversity and Critical Ecosystem Services? Oryx 49 (01), 74-79. DOI:10.1017/ S0030605313001348.

Lynam, T.; de Jong, W.; Sheil, D.; Kusumanto, T. \& Evans, K. 2007. A Review of Tools for Incorporating Community Knowledge, Preferences, and Values into Decision Making in Natural Resources Management. Ecology and Society 12 (1). http:// www.ecologyandsociety.org/vol12/iss1/art5/. (Date: 25.07.2019)

Mace, G. M.; Norris, K. \& Fitter, A. H. 2012. Biodiversity and Ecosystem Services: A Multilayered Relationship. Trends in Ecology \& Evolution 27 (1), 19-26. DOI:10.1016/j.tree.2011.08.006. 
Marino, D.; Schirpke, U.; Gaglioppa, P.; Marucci, A.; Palmieri, M.; Pellegrino, D.; De Marco, C. \& Scolozzi, R. 2014. Assessment And Governance Of Ecosystem Services First Insights From Life+ Making Good Natura Project. Annali Di Botanica 4, 83-90. DOI:10.4462/annbotrm-11600.

Meadows, D. 1999. Leverage Points: Places to Intervene in a System. Hartland, Vermont: The Sustainability Institute. http://donellameadows. org/archives/leverage-points-places-tointervene-in-a-system(Date: 23.04.2019)

Medema, W.; Wals, A. \& Adamowski, J. 2014. Multi-Loop Social Learning for Sustainable Land and Water Governance: Towards a Research Agenda on the Potential of Virtual Learning Platforms. NJAS - Wageningen Journal of Life Sciences, Social learning towards sustainability: problematic, perspectives and promise, 69, 2338. DOI:10.1016/j.njas.2014.03.003.

Millennium Ecosystem Assessment, 2003. Ecosystems and Human Well-Being: A Framework for Assessment. Millennium Ecosystem Assessment, Island Press, Washington, DC.

Moreno, J.; Palomo, I.; Escalera, J.; Martín-López, B. \& Montes, C. 2014. Incorporating ecosystem services into ecosystem-based management to deal with complexity: a participative mental model approach. Landscape Ecology, 29(8), 1407-1421. DOI: 10.1007/s10980-014-0053-8

Özesmi, U. \& Özesmi, S. L. 2004. Ecological Models Based on People's Knowledge: A Multi-Step Fuzzy Cognitive Mapping Approach. Ecological Modelling 176 (1), 43-64. DOI:10.1016/j. ecolmodel.2003.10.027.

Palomo, I.; Montes, C.; Martín-López, B.; González, J. A.; García-Llorente, M.; Alcorlo, P. \& García Mora, M.R. 2014. Incorporating the Social-Ecological Approach in Protected Areas in the Anthropocene. BioScience. DOI:10.1093/biosci/bit033.
Partelow, S. \& Winkler, K. 2016. Interlinking Ecosystem Services and Ostrom's Framework through Orientation in Sustainability Research. Ecology and Society 21 (3). DOI:10.5751/ES08524-210327.

Pérez-Miñana, E. 2016. Improving Ecosystem Services Modelling: Insights from a Bayesian Network Tools Review. Environmental Modelling \& Software 85, 184-201. DOI:10.1016/j.envsoft.2016.07.007.

Pickering, C. M. \& Hill, W. 2007. Impacts of Recreation and Tourism on Plant Biodiversity and Vegetation in Protected Areas in Australia. Journal of Environmental Management 85 (4), 791-800. DOI:10.1016/j.jenvman.2006.11.021.

Rouwette, E. A.; Vennix, J. A. \& Thijssen, C. M. 2000. Group model building: A decision room approach. Simulation \& Gaming, 31(3), 359-379. DOI:10.1177/104687810003100303.

Schirpke, U.; Marino, D.; Marucci, A.; Palmieri, M. \& Scolozzi, R. 2017. Operationalising Ecosystem Services for Effective Management of Protected Areas: Experiences and Challenges. Ecosystem Services, 28, 105-114.

Scolozzi, R.; Soane, I. D. \& Gretter, A. 2014. MultipleLevel Governance Is Needed in the SocialEcological System of Alpine Cultural Landscapes. In Frans Padt, Paul Opdam, Nico Polman, and CatrienTermeer(eds.) Scale-Sensitive Governance of the Environment, 90-105. John Wiley \& Sons, Ltd.

Senge, P. 1990. The fifth Discipline: The Art and Practice of the Learning Organization. London: Doubleday Currency. 
Smith, R.I.; Barton, D.N.; Dick, J.; Haines-Young, R.; Madsen, A.L.; Rusch, G.M.; Termansen, M.; Woods, H.; Carvalho, L.; Giucă, R.C., Luque, S., Odee, D., Rusch, V.; Saarikoski, H.; Adamescu, C.M.; Dunfordm, R.; Ochieng. J.; GonzalezRedin, J.; Stange, E.; Vădineanu, A.; Verweij, P. \& Vikström, S. 2018. Operationalising ecosystem service assessment in Bayesian Belief Networks: experiences within the OpenNESS project. Ecosystem Services, 29, 452-464. DOI: 10.1016/j. ecoser.2017.11.004

Sonter, L. J.; Watson, K. B.; Wood, S. A. \& Ricketts, T. H. 2016. Spatial and Temporal Dynamics and Value of Nature-Based Recreation, Estimated via Social Media. PLOS ONE 11 (9), e0162372. DOI:10.1371/journal.pone.0162372.

Spangenberg, J. H.; Görg, C. \& Settele, J. 2015. Stakeholder Involvement in ESS Research and Governance: Between Conceptual Ambition and Practical Experiences - Risks, Challenges and Tested Tools. Ecosystem Services 16, 201-211. DOI:10.1016/j.ecoser.2015.10.006.

Sterman, J. D. 2000. Business Dynamics: Systems Thinking and Modeling for a Complex World. Vol. 19. Boston: McGraw-Hill.

Sturmberg, J.P., Churilov, L. \& McDonnell, G. 2013. Modelling. In Handbook of Systems and Complexity in Health, 81-111. New York: Springer.

Sun, Z. \& Müller, D. 2013. A Framework for Modeling Payments for Ecosystem Services with AgentBased Models, Bayesian Belief Networks and Opinion Dynamics Models. Environmental Modelling \& Software 45, 15-28. DOI:10.1016/j. envsoft.2012.06.007

Sweeney, L. B. \& Sterman, J. D. 2000. Bathtub Dynamics: Initial Results of a Systems Thinking Inventory. System Dynamics Review 16 (4): 249286. DOI:10.1002/sdr.198.
TEEB. 2010. The Economics of Ecosystems and Biodiversity: Ecological and Economic Foundations. London and Washington: edited by Pushpam Kumar, Earthscan. http://www. teebweb.org/teeb-study-and-reports/mainreports/ecological-and-economic-foundations/. (Date: 25.07.2019)

Tsoularis, A. \& Wallace, J. 2002. Analysis of Logistic Growth Models. Mathematical Biosciences 179 (1), 21-55. DOI:10.1016/S0025-5564(02)000962.

Vennix, J. A. M. 1999. Group Model-Building: Tackling Messy Problems. System Dynamics Review 15 (4), 379-401. DOI: 10.1002/(SICI)10991727(199924)15:4<345::AID-SDR177>3.0.CO;2-Z

Videira, N.; Antunes, P.; Santos, R. \& Gamito, S. 2003. Participatory Modelling in Environmental Decision-Making: The Ria Formosa Natural Park Case Study. Journal of Environmental Assessment Policy and Management 5 (03): 421-447. DOI: 10.1142/S1464333203001371

Voinov, A. \& Bousquet, F. 2010. Modelling with Stakeholders. Thematic Issue - Modelling with Stakeholders 25 (11): 1268-1281. DOI:10.1016/j. envsoft.2010.03.007.

Watson, J. E. M.; Dudley, N.; Segan, D. B. \& Hockings, M. 2014. The Performance and Potential of Protected Areas. Nature 515 (7525), 67-73. DOI:10.1038/nature13947.

Westgate, M. J.; Likens, G. E. \& Lindenmayer, D. B. 2013. Adaptive Management of Biological Systems: A Review. Biological Conservation 158, 128-139. DOI:10.1016/j.biocon.2012.08.016. 